adw. dr Piotr Sobański LL.M. (Zielona Góra)

piotr.sobanski@adwokatura.pl

\title{
Kwestia konieczności przyjęcia ustawy reprywatyzacyjnej w świetle art. 1 Protokołu Nr 1 do EKPC
}

\section{Uwagi wstępne}

Reprywatyzację można określić jako proces zmierzający do zwrotu znacjonalizawanego mienia na rzecz dawnych właścicieli lub wypłacenia im odszkodowania z tytułu wywłaszczenia.

W Polsce nie została po 1989 r. dokonana kompleksowa reprywatyzacja, która odniosłaby się do wszelkich kategorii mienia dotkniętego nacjonalizacją. W latach 19892015 do Sejmu trafiło 18 projektów ustaw podejmujących problem reprywatyzacji w sposób kompleksowy i systemowy, z czego tylko jedna tego rodzaju ustawa została uchwalona, choć nie weszła w życie ${ }^{1}$. Warto przy tym wspomnieć, że w art. 2 ust. 1 Ustawy z dnia 7 marca 2001 r. o reprywatyzacji, która została zawetowana przez Prezydenta znajduje się szczegółowy katalog aktów normatywnych o charakterze wywłaszczeniowym i konfiskacyjnym.

W Polsce zostały przyjęte jedynie tzw. sektorowe ustawy reprywatyzacyjne, które odnosiły się do określonych kategorii wywłaszczonego mienia i określonych podmiotów dotkniętych nacjonalizacją ${ }^{2}$

Polska ratyfikowała w 1993 r. Europejską Konwencję o Ochronie Praw Człowieka i Podstawowych Wolności z dnia 4 listopada 1950 r. $^{3}$, a dnia 10 października 1994 r. Protokół Nr 1 z dnia 20 marca 1952 r. do Konwencji o Ochronie Praw Człowieka i Podstawowych Wolności ${ }^{4}$.

Niniejszy artykuł analizuje kwestie ewentualnej konieczności przyjęcia kompleksowej ustawy reprywatyzacyjnej w oparciu o art. 1 Protokołu $\mathrm{Nr} 1$ do EKPC, przy uwzględnieniu bogatego orzecznictwa ETPC dotyczącego wykładni i stosowania art. 1. Rozważania zawarte w niniejszym artykule nie odnoszą się do spraw przeciwko Polsce, w których skarżący zarzucali naruszenie art. 6 EKPC podczas postępowań przed polskimi sądami, dotyczących zwrotu wywłaszczonego mienia względnie odszkodowania z tytułu wywłaszczenia. Artykuł nie analizuje orzecznictwa ETPC w zakresie dotyczącym naruszenia art. 14 EKPC m.in. dlatego, że art. 14 nie może być samoistną podstawą skargi do ETPC, ma charakter akcesoryjny wobec innych chronionych praw. W określonych sytuacjach naruszenie art. 14 EKPC może być oczywiście zarzucane państwu, m.in. w związku z art. 1 Protokołu Nr 1 do EKPC lub art. 6 EKPC. Zastosowanie art. 14 EKPC w związku z art. 1 Protokołu Nr 1 wymagałoby jednak wykazania, że naruszenie zasady niedyskryminacji wiązało się ściśle z naruszeniem prawa własności ${ }^{5}$.

1 K. Dobrzeniecki, M. Romanowski, Reprywatyzacja: problemy tworzenia $i$ stosowania prawa, Wydawnictwo Uniwersytetu Kardynała Stefana Wyszyńskiego, Warszawa 2015, s. 77; J. Rudzka, A. Semenowicz, R. Stawicki, Problematyka reprywatyzacji w świetle projektów ustaw w latach 1989-2010, ze szczególnym uwzględnieniem propozycji ostatnich regulacji, Biuro Analiz i Dokumentacji Kancelarii Senatu, Warszawa 2010, s. 22.

2 Szerzej: K. Dobrzeniecki, M. Romanowski, op. cit., s. 93-110.

3 Dz. U. z dnia 10 lipca 1993 r., Nr 61, poz. 284.

4 Dz. U. z dnia 4 kwietnia 1995 r., Nr 36, poz. 175.

5 Por. V. Zagórowska, Odpowiedzialność państwa za naruszenie praw mniejszości narodowych - słabości międzynarodowego systemu ich ochrony [w:] Odpowiedzialność międzynarodowa w związku z naruszeniami praw człowieka i międzynarodowego prawa humanitarnego, red. M. Balcerzak, J. 
W artykule została pominięta ocena przyczyn braku przyjęcia przez ustawodawcę przez trzy dekady kompleksowej ustawy reprywatyzacyjnej.

\section{Pojęcie mienia w rozumieniu art. 1 Protokołu Nr 1 do EKPC}

W art. 1 Protokołu Nr 1 do EKPC została wprowadzona ochrona własności ${ }^{6}$. Brak uregulowania w EKPC ochrony własności nie jest wynikiem przeoczenia, lecz braku politycznej zgody co do uznania prawa własności za jedno z praw człowieka ${ }^{7}$. Idea ochrony własności jako prawa człowieka od początku wywoływała wiele dyskusji. Jak wskazuje M. A. Nowicki „przedmiotem sporu była m.in. kwestia, czy w ogóle należy rozważać włączenie go do katalogu praw, które miały być zagwarantowane w Konwencji. Szczególne kontrowersje wywołał problem odszkodowań w przypadku pozbawienia mienia $w$ drodze nacjonalizacji. One właśnie były powodem zaniechania umieszczenia tego prawa w zasadniczym tekście Konwencji. Stąd protokół dodatkowy"8. Przyjęcie art. 1 Protokołu nr 1 do EKPC należy zatem traktować jako rezultat kompromisu państw, będących członkami Rady Europy ${ }^{9}$.

Naruszenie art. 1 Protokołu Nr 1 może być zarzucane jedynie w zakresie, w jakim kwestionowane decyzje odnosiły się do mienia skarżącego w rozumieniu art. 1 Protokołu $\mathrm{Nr} 1^{10}$. Pojęcie mienia, o którym mowa w art. 1 Protokołu $\mathrm{Nr} 1$, nie jest ograniczone do własności dóbr fizycznych. Ma ono znaczenie autonomiczne i jest niezależne od formalnej klasyfikacji przyjętej przez prawo danego państwa ${ }^{11}$. Inne niż własność prawa i interesy

Kapelańska-Pręgowska, Katedra Praw Człowieka, Wydział Prawa i Administracji, Uniwersytet Mikołaja Kopernika, Toruń 2016, s. 213; M. Ciesielska, Zakaz dyskryminacji i zasada równości w regionalnych systemach ochrony praw człowieka na przykładzie Europejskiej Konwencji Praw Człowieka i Arabskiej Karty Praw Człowieka [w:] Ochrona praw człowieka w wymiarze regionalnym, red. M. Marcinko, Ośrodek Międzynarodowego Prawa Humanitarnego i Praw Człowieka Wydziału Prawa i Administracji Uniwersytetu Jagiellońskiego, Kraków 2012, s. 23; W. M. Góralski, Przejęcie własności niemieckiej przez Państwo Polskie po drugiej wojnie światowej na Ziemiach Zachodnich i Północnych a niemieckie roszczenia odszkodowawcze, Warszawa 2004 (http://uwlaszczenia.gabo.pl/dok1.php?id=126) [data dostępu: 20 lipca 2019 r.].

6 Art. 1 zatytułowany „Ochrona własności” brzmi następująco: „Każda osoba fizyczna i prawna ma prawo do poszanowania swego mienia. Nikt nie może być pozbawiony swojej własności, chyba że w interesie publicznym i na warunkach przewidzianych przez ustawę oraz zgodnie z ogólnymi zasadami prawa międzynarodowego.

Powyższe postanowienia nie będą jednak w żaden sposób naruszać prawa państwa do stosowania takich ustaw, jakie uzna za konieczne do uregulowania sposobu korzystania z własności zgodnie z interesem powszechnym lub w celu zabezpieczenia uiszczania podatków bądź innych należności lub kar pieniężnych".

7 K. Przybyszewski, Prawa człowieka w kontekstach kulturowych, Wydawnictwo Naukowe Instytutu Filozofii Uniwersytetu im. Adama Mickiewicza w Poznaniu, Poznań 2010, s. 67.

8 M. A. Nowicki, Komentarz do art. 1 Protokołu $\mathrm{Nr} 1$ do Konwencji o ochronie praw człowieka i podstawowych wolności, LEX 2017.

9 Ł. Duda, J. Kociubiński, Realizacja ochrony własności w Europejskiej Konwencji Praw Człowieka na podstawie orzeczenia Lithgow i inni (http://www.bibliotekacyfrowa.pl/Content/34400/0015.pdf) [data dostępu: 25 lipca 2019 r.].

10 Decyzja ETPC z dnia 2 marca 2005 r., skargi nr 71916/01, 71917/01, 10260/02, Maltzan i inni, Zitzewitz i inni oraz Man Ferrostaal i Alfred Toepfer-Stiftung v. Niemcy, LEX nr 147231; Wyrok ETPC z dnia 28 września 2004 r., Kopecký v. Słowacja.

11 Wyrok ETPC z dnia 7 lipca 2009 r., skarga nr 22279/04, Plechanow v. Polska, LEX nr 504446; Wyrok ETPC z dnia 21 czerwca 2011 r., skarga nr 46575/09, Bellizzi v. Malta, LEX nr 846299; Decyzja ETPC z dnia 9 października 2012 r., skarga nr 26501/05, Eparhija Budimljansko-nikšićka i inni v. Czarnogóra, LEX nr 1285512; Wyrok ETPC z dnia 7 lutego 2013 r., skarga nr 16574/08, Fabris v. Francja, LEX nr 1260966; Wyrok ETPC z dnia 14 maja 2013 r., skarga nr 66529/11, N. K. M. v. Węgry, LEX nr 1771580. 
składające się na majątek mogą być również postrzegane jako prawa majątkowe, a tym samym jako mienie" $w$ rozumieniu art. 1 Protokołu $\mathrm{Nr} 1^{12}$. Mienie może być istniejącym mieniem lub aktywami ${ }^{13}$.

Osoba zaskarżająca naruszenie jej prawa majątkowego musi udowodnić istnienie tego prawa ${ }^{14}$. W każdym postępowaniu ETPC musi rozstrzygnąć, czy okoliczności danej sprawy, postrzegane jako całość, dawały skarżącemu tytuł do interesu materialnoprawnego, który jest chroniony przez art. 1 Protokołu Nr 1, a tym samym czy przepis ten znajduje zastosowanie w sprawie ${ }^{15}$.

Mienie może w określonych sytuacjach obejmować nawet roszczenia ${ }^{16}$. Aby roszczenie mogło zostać uznane za aktywa wchodzące w zakres stosowania art. 1 Protokołu $\mathrm{Nr}$ 1, skarżący powinien wykazać, że ma ono wystarczające podstawy w prawie krajowym ${ }^{17}$. Wystarczająca podstawa $w$ prawie krajowym występuje wówczas, gdy roszczenie jest wystarczająco ustalone, by można go było dochodzić ${ }^{18}$. Warto wspomnieć, że nie podlega ochronie przewidzianej art. 1 Protokołu $\mathrm{Nr} 1$ warunkowe roszczenie, które upadło w wyniku niespełnienia warunku ${ }^{19}$.

Sama nadzieja, że może zostać przywrócone prawo własności, którego już od dawna nie można skutecznie wykonywać i które zostało utracone przed wejściem w życie w stosunku do państwa Protokołu Nr 1, nie może być uznane za mienie w rozumieniu art. 1 Protokołu $\mathrm{Nr} 1^{20}$. Gdy przedmiotem skargi jest roszczenie, skarżący może natomiast argumentować i dowodzić, że ma przynajmniej uzasadnione prawnie oczekiwanie uzyskania efektywnego korzystania z prawa majątkowego ${ }^{21}$. ETPC rozgranicza w swoim orzecznictwie konsekwentnie nadzieję od uzasadnionej prawnie ekspektatywy, która musi mieć bardziej konkretny charakter niż sama nadzieja skarżącego i być bardziej od niej realna ${ }^{22}$

12 Wyrok ETPC z dnia 7 lutego 2013 r., Fabris v. Francja; Wyrok ETPC z dnia 21 czerwca 2011 r., Bellizzi v. Malta.

13 Wyrok ETPC z dnia 21 czerwca 2011 r., Bellizzi v. Malta; Wyrok ETPC z dnia 28 września 2004 r., Kopecký v. Słowacja.

14 Decyzja ETPC z dnia 6 kwietnia 2000 r., skarga nr 33776/96, P. Potocka, P. Potocki, D. PotockaRadziwiłt, A. Potocka i I. d'Ornano v. Polska, LEX nr 41143; Decyzja ETPC z dnia 27 stycznia 2000 r., skarga nr 33752/96, Rucińska v. Polska, LEX nr 41130.

15 Wyrok ETPC z dnia 29 maja 2012 r., skarga nr 2489/09, Flores Cardoso v. Portugalia, LEX nr 1164651; Decyzja ETPC z dnia 17 grudnia 2013 r., skarga nr 49893/07, Crash 2000 OOD i inni v. Bułgaria, LEX nr 1409586; Wyrok ETPC z dnia 14 maja 2013 r., N. K. M. v. Węgry; Wyrok ETPC z dnia 21 czerwca 2011 r., Bellizzi v. Malta.

16 Por. Wyrok ETPC z dnia 21 czerwca 2011 r., Bellizzi v. Malta; Decyzja ETPC z dnia 17 maja 2016 r., skarga nr 8585/13, Piekarska i inni v. Polska, LEX nr 2051117.

17 Wyrok ETPC z dnia 20 maja 2010 r., skarga nr 55555/08, Lelas v. Chorwacja, LEX nr 578480; Wyrok ETPC z dnia 6 października 2005 r., skarga nr 1513/03, Draon v. Francja, LEX nr 157767.

18 Wyrok ETPC z dnia 20 maja 2010 r., Lelas v. Chorwacja.

19 Wyrok ETPC z dnia 4 marca 2003 r., skarga nr 39050/97, Jantner v. Słowacja, LEX nr 77471; Wyrok ETPC z dnia 7 lutego 2013 r., Fabris v. Francja; Decyzja ETPC z dnia 17 maja 2016 r., Piekarska i inni v. Polska.

20 Por. Decyzja ETPC z dnia 11 grudnia 2018 r., skarga nr 41178/12, Rał v. Polska, LEX nr 2627060; Wyrok ETPC z dnia 4 marca 2003 r., Jantner v. Słowacja; Wyrok ETPC z dnia 7 lutego 2013 r., Fabris v. Francja; Decyzja ETPC z dnia 9 października 2012 r., Eparhija Budimljansko-nikšićka i inni v. Czarnogóra; Decyzja ETPC z dnia 5 kwietnia 2018 r., skarga nr 32045/10, Kościół Chrześcijan Baptystów we Wrocławiu v. Polska, LEX nr 2467650.

21 Por. Wyrok ETPC z dnia 14 maja 2013 r., N. K. M. v. Węgry; Wyrok ETPC z dnia 7 stycznia 2003 r., skarga nr 44912/98, Kopecký v. Słowacja, LEX nr 75679; Wyrok ETPC z dnia 4 marca 2003 r., Jantner v. Słowacja; Decyzja ETPC z dnia 27 stycznia 2000 r., Rucińska v. Polska; Decyzja ETPC z dnia 6 kwietnia 2000 r., P. Potocka, P. Potocki, D. Potocka-Radziwiłł, A. Potocka i l. d'Ornano v. Polska.

22 Por. Decyzja ETPC z dnia 9 października 2012 r., Eparhija Budimljansko-nikšićka i inni v. Czarnogóra; 
Uzasadniona prawnie ekspektatywa może opierać się na przepisie prawnym lub na ostatecznym orzeczeniu sądowym ${ }^{23}$. Należy jednak podkreślić, że uprawniona ekspektatywa nie powstaje wówczas, gdy zachodzi spór co do prawidłowej wykładni i stosowania prawa krajowego, a prezentowane przez skarżącego stanowisko było odrzucone przez sądy krajowe ${ }^{24}$. ETPC wyraża pogląd w orzecznictwie, że decydująca przy rozstrzyganiu w przedmiocie skargi nie jest okoliczność istnienia rzeczywistego sporu lub dającego się uzasadnić roszczenia skarżącego ${ }^{25}$.

Roszczenie skarżącego może być postrzegane jako podlegające ochronie art. 1 Protokołu Nr 1 aktywa także wówczas, gdy istnieje potwierdzająca to linia orzecznicza sądów krajowych ${ }^{26}$. Jest to kolejny przykład na wykazanie istnienia uzasadnionej ekspektatywy. Nie mogą jednak istnieć kontrowersje w linii orzeczniczej co do sposobu, w jaki prawo krajowe winno być prawidłowo interpretowane i stosowane ${ }^{27}$. Uprawniona ekspektatywa nie stanowi zatem mienia, jeżeli dany interes majątkowy nie znajduje potwierdzenia w ustalonym orzecznictwie sądów krajowych. Linia orzecznicza sądów powinna być jednolita, co niejednokrotnie podkreślał ETPC ${ }^{28}$.

W omawianym zakresie warto odnieść się do wyroku ETPC wydanego w sprawie Broniowski v. Polska, w którym uprawnienie skarżącego, określone jako "prawo do zaliczenia" zostało uznane za "konkretne prawo majątkowe" o "wartości majątkowej" przez Trybunał Konstytucyjny i Sąd Najwyższy. Spowodowało to uznanie przez ETPC, że uprawnienie skarżącego stanowiło "mienie" w rozumieniu art. 1 Protokołu $\mathrm{Nr} 1$. Zarzuty dotyczyły braku realizacji przez Polskę uprawnienia do rekompensaty, które prawo polskie niezmiennie przyznawało skarżącemu, tj. przed ratyfikacją Protokołu $\mathrm{Nr} 1$, a także w momencie wydania decyzji o dopuszczalności skargi ${ }^{29}$.

\section{Jurysdykcja temporalna ETPC w sprawach dotyczących pozbawienia własności}

ETPC wskazywał niejednokrotnie w orzecznictwie, że pozbawienie własności jest co do zasady jednorazowym zdarzeniem i nie tworzy trwałej sytuacji pozbawienia prawa ${ }^{30}$.

Przekonanie, że prawo obowiązujące podczas dokonanego przed ratyfikacją wywłaszczenia zostanie zmienione, nie może zostać uznane za uzasadnioną prawnie

Wyrok ETPC z dnia 29 maja 2012 r., Flores Cardoso v. Portugalia; Decyzja ETPC z dnia 2 maja 2017 r., skarga nr 55537/10, Haupt v. Austria, LEX nr 2297380; Wyrok ETPC z dnia 28 września 2004 r., Kopecký v. Słowacja; Decyzja ETPC z dnia 3 października 2017 r., skarga nr 1680/08, Lubelska Fabryka Maszyn i Narzędzi Rolniczych 'Plon' i inni v. Polska, LEX nr 2381150.

23 Por. Decyzja ETPC z dnia 9 października 2012 r., Eparhija Budimljansko-nikšićka i inni v. Czarnogóra; Wyrok ETPC z dnia 7 lipca 2009 r., Plechanow v. Polska.

24 Wyrok ETPC z dnia 29 maja 2012 r., Flores Cardoso v. Portugalia; Decyzja ETPC z dnia 17 grudnia 2013 r., Crash 2000 OOD i inni v. Bułgaria.

25 Wyrok ETPC z dnia 28 września 2004 r., Kopecký v. Słowacja.

26 Decyzja ETPC z dnia 3 października 2017 r., Lubelska Fabryka Maszyn i Narzędzi Rolniczych 'Plon' i inni v. Polska; Wyrok ETPC z dnia 7 lipca 2009 r., Plechanow v. Polska.

27 Wyrok ETPC z dnia 14 maja 2013 r., N. K. M. v. Węgry; Wyrok ETPC z dnia 29 maja 2012 r., Flores Cardoso v. Portugalia.

28 Wyrok ETPC z dnia 28 września 2004 r., Kopecký v. Słowacja; Wyrok ETPC z dnia 29 maja 2012 r., Flores Cardoso v. Portugalia; Wyrok ETPC z dnia 21 czerwca 2011 r., Bellizzi v. Malta.

29 Szerzej: Wyrok ETPC z dnia 22 czerwca 2004 r., skarga nr 31443/96, Broniowski v. Polska, LEX nr 122528; Decyzja ETPC z dnia 19 grudnia 2002 r., skarga nr 31443/96, Broniowski v. Polska, LEX nr 56798.

30 Decyzja ETPC z dnia 2 marca 2005 r., Maltzan i inni, Zitzewitz i inni oraz Man Ferrostaal i Alfred ToepferStiftung v. Niemcy; Wyrok ETPC z dnia 28 września 2004 r., Kopecký v. Słowacja; Decyzja ETPC z dnia 13 grudnia 2000 r., skarga nr 33071/96, Malhous v. Czechy, LEX nr 148771. 
ekspektatywę dla celów art. 1 Protokołu $\mathrm{Nr} 1^{31}$.

Trybunał jest właściwy ratione temporis jedynie wobec zdarzeń objętych przepisami Protokołu $\mathrm{Nr} 1$, do których doszło po dacie jego ratyfikacji ${ }^{32}$. Niezgodność skargi ratione temporis z postanowieniami EKPC i Protokołów skutkuje odrzuceniem skargi zgodnie z art. 35 ust. $4 \mathrm{EKPC}^{33}$.

Od daty ratyfikacji wszystkie zachowania przypisywane państwu muszą być zgodne z EKPC i Protokołami, a późniejsze okoliczności faktyczne wchodzą w zakres jurysdykcji ETPC nawet wówczas, gdy są one tylko przedłużeniem już istniejącej sytuacji ${ }^{34}$. O ile ETPC nie ma jurysdykcji temporalnej do zbadania faktów przed datą, kiedy Protokółu Nr 1 został ratyfikowany, to może wziąć pod uwagę fakty zaistniałe przed ratyfikacją tak dalece, jak mogą one zostać uznane za okoliczności, które wywołały sytuację rozciągającą się poza datę ratyfikacji, lub które mogą mieć znaczenie dla zrozumienia zdarzeń po tej dacie $^{35}$.

W orzecznictwie ETPC odnosił się do mającego wpływ na temporalne ograniczenie jurysdykcji tzw. ciągłego naruszenia EKPC i Protokołu $\mathrm{Nr} 1$, tj. sytuacji, która powstała przed ratyfikacją EKPC i Protokołu, lecz utrzymuje się po tej dacie ${ }^{36}$. W sprawie Broniowski v. Polska ETPC uznał jurysdykcję temporalną dla zbadania skargi, w której zarzuty odnosiły się do działań i zaniechań państwa w stosunku do wykonania uprawnienia do środka odszkodowawczego przyznanego zabużanom - w tym skarżącemu - na mocy prawa krajowego ${ }^{37}$.

Art. 1 Protokołu Nr 1 do Konwencji ma na celu ochronę niezakłóconego korzystania $\mathrm{z}$ istniejącego mienia ${ }^{38}$. ETPC konsekwentnie wskazywał, że art. 1 Protokołu $\mathrm{Nr} 1$ nie gwarantuje prawa do nabycia własności ${ }^{39}$.

\section{Możliwość ingerencji przez państwo w zasadę poszanowania mienia}

\section{W myśl art. 1 ust. 1 Protokołu Nr 1 pozbawienie własności może nastąpić na}

31 Decyzja ETPC z dnia 9 października 2012 r., Eparhija Budimljansko-nikšićka i inni v. Czarnogóra.

32 Por. Decyzja ETPC z dnia 6 kwietnia 2000 r., P. Potocka, P. Potocki, D. Potocka-Radziwiłł, A. Potocka i I. d'Ornano v. Polska.

33 Decyzja ETPC z dnia 7 października 2008 r., skarga nr 47550/06, Preussische Treuhand GmbH \& CO. Kg A. A. v. Polska, LEX nr 457001.

34 Decyzja ETPC z dnia 7 października 2008 r., Preussische Treuhand GmbH \& CO. Kg A. A. v. Polska.

35 Wyrok ETPC z dnia 15 grudnia 2015 r., skarga nr 32794/07, Matczyński v. Polska, LEX nr 1936311.

36 Por. Wyrok ETPC z dnia 23 marca 1995 r., skarga nr 15318/89, Loizidou v. Turcja, LEX nr 80428; szerzej na temat ciągłego naruszenia prawa: M. Balcerzak, Odpowiedzialność państwa-strony Europejskiej konwencji o ochronie praw człowieka i podstawowych wolności. Studium prawnomiędzynarodowe, Wydawnictwo Dom Organizatora, Toruń 2013, s. 117-121; A. Czaplińska, Określanie własnej kompetencji przez sądy międzynarodowe - granica czy przejaw swobody orzeczniczej? [w:] Granice swobody orzekania sądów międzynarodowych, red. A. Wyrozumska, Seria Wydawnicza Katedry Europejskiego Prawa Konstytucyjnego Wydział Prawa i Administracji Uniwersytetu Łódzkiego, Łódź 2014, s. 99-100.

37 Decyzja ETPC z dnia 19 grudnia 2002 r., Broniowski v. Polska; Wyrok ETPC z dnia 22 czerwca 2004 r., Broniowski v. Polska.

38 Decyzja ETPC z dnia 27 stycznia 2000 r., Rucińska v. Polska; Decyzja ETPC z dnia 6 kwietnia 2000 r., P. Potocka, P. Potocki, D. Potocka-Radziwiłł, A. Potocka i I. d'Ornano v. Polska.

39 Decyzja ETPC z dnia 5 kwietnia 2018 r., Kościół Chrześcijan Baptystów we Wrocławiu v. Polska, decyzja ETPC z dnia 13 marca 2018 r., skarga nr 45651/11, Dobrowolski i inni v. Polska, LEX nr 2467651; wyrok ETPC z dnia 4 marca 2003 r., Jantner v. Słowacja; Decyzja ETPC z dnia 27 stycznia 2000 r., Rucińska v. Polska; Decyzja ETPC z dnia 6 kwietnia 2000 r., P. Potocka, P. Potocki, D. Potocka-Radziwiłł, A. Potocka i I. d'Ornano v. Polska; Decyzja ETPC z dnia 23 stycznia 2018 r., skarga nr 12792/13, Wysowska v. Polska, LEX nr 2442318; Decyzja ETPC z dnia 23 października 2012 r., skarga nr 34880/12, N. K. M. v. Węgry, LEX nr 1285616. 
warunkach przewidzianych przez ustawę oraz zgodnie z ogólnymi zasadami prawa międzynarodowego.

Najważniejszym wymogiem art. 1 ust. 1 Protokołu $\mathrm{Nr} 1$ jest wymóg, aby wszelkie ingerencje ze strony organu władzy publicznej w poszanowanie mienia były zgodne $z$ prawem $^{40}$. Zasada zgodności z prawem zakłada, że odnośne przepisy prawa krajowego są wystarczająco dostępne, dokładne, a także przewidywalne w swym stosowaniu ${ }^{41}$. Ogólne zasady prawa międzynarodowego, o których mowa w art. 1 ust. 1 odnoszą się wyłącznie do własności należącej do cudzoziemców i wynika z nich obowiązek zapłaty odszkodowania ${ }^{42}$. Zasady te kształtowały się najpierw wśród państw zachodnich. W tym zakresie można odnieść się m.in. do tzw. doktryny Hulla, uzależniającej wywłaszczenie od zapłaty odszkodowania, które ma być natychmiastowe, odpowiednie i efektywne ${ }^{43}$. Obecnie obowiązek odszkodowawczy należy uznać w prawie międzynarodowym za bezsporny.

W myśl art. 1 ust. 1 Protokołu $\mathrm{Nr} 1$ pozbawienie własności może nastąpić w interesie publicznym. ETPC wskazywał w orzecznictwie, że państwo cieszy się szerokim marginesem uznania co do tego, co jest zgodne $z$ interesem publicznym ${ }^{44}$. Ponadto pojęcie interesu publicznego jest $z$ założenia szerokie ${ }^{45}$. ETPC uznaje osąd prawodawcy dotyczący tego, co leży w interesie publicznym, chyba że jest on w sposób oczywisty pozbawiony rozsądnej podstawy ${ }^{46}$.

Zgodnie z art. 1 ust. 2 Protokołu Nr 1 postanowienia zawarte w ust. 1 nie będą jednak w żaden sposób naruszać prawa państwa do stosowania takich ustaw, jakie uzna za konieczne do uregulowania sposobu korzystania z własności zgodnie z interesem powszechnym lub w celu zabezpieczenia uiszczania podatków bądź innych należności lub kar pieniężnych.

Ingerencja państwa $\mathrm{w}$ zasadę poszanowania mienia powinna utrzymywać sprawiedliwą równowagę pomiędzy wymogami publicznego lub powszechnego interesu społeczeństwa a wymaganiami ochrony praw podstawowych jednostki, co wynika z treści art. 1 Protokołu $\mathrm{Nr} 1^{47}$. Określając czy istnieje tego rodzaju równowaga, ETPC uznaje, że państwa dysponuja szerokim marginesem uznania w zakresie wyboru środków i oceny, czy konsekwencje danego działania są usprawiedliwione ochroną interesu ogólnego w osiągnięciu danego celu ${ }^{48}$. Wymagana sprawiedliwa równowaga nie jest zachowana, gdy

40 Wyrok ETPC z dnia 15 grudnia 2015 r., Matczyński v. Polska; Wyrok ETPC z dnia 28 czerwca 2018 r., skarga nr 1828/06, G.I.E.M. S.R.L. i inni v. Włochy, LEX nr 2508455.

41 Wyrok ETPC z dnia 7 czerwca 2012 r., skarga nr 38433/09, Centro Europa 7 S.r.l. i Di Stefano v. Włochy, LEX nr 1164402.

42 M. A. Nowicki, Komentarz do art. 1 Protokołu $\mathrm{Nr} 1$ do Konwencji o ochronie praw człowieka i podstawowych wolności, LEX 2017.

43 Szerzej: P. Sobański, Roszczenia Polski wobec RFN w świetle doktryny niemieckiej, Wydawnictwo Naukowe Wyższej Szkoły Pedagogiki i Administracji im. Mieszka I w Poznaniu, Poznań 2019, s. 235-237.

44 Wyrok ETPC z dnia 15 grudnia 2015 r., Matczyński v. Polska; Decyzja ETPC z dnia 6 grudnia 2011 r., skarga nr 44232/11, Mihăieş i Senteş v. Rumunia, LEX nr 1101154.

45 Wyrok ETPC z dnia 13 grudnia 2016 r., skarga nr 53080/13, Béláné Nagy v. Węgry, LEX nr 2165716; Wyrok ETPC z dnia 17 kwietnia 2012 r., skarga nr 31925/08, Grudić v. Serbia, LEX nr 1147983.

46 Por. Decyzja ETPC z dnia 6 grudnia 2011 r., Mihăieş i Senteş v. Rumunia; Wyrok ETPC z dnia 16 lipca 2014 r., skarga nr 60642/08, Ališić i inni v. Bośnia-Hercegowina, Chorwacja, Macedonia, Serbia i Słowenia, LEX nr 1487006.

47 Decyzja ETPC z dnia 6 grudnia 2011 r., Mihăieş i Senteş v. Rumunia; Wyrok ETPC z dnia 17 kwietnia 2012 r., Grudić v. Serbia; Wyrok ETPC z dnia 14 maja 2013 r., N. K. M. v. Węgry; Wyrok ETPC z dnia 16 listopada 2004 r., skarga nr 41673/98, Bruncrona v. Finlandia, LEX nr 142265; Wyrok ETPC z dnia 16 lipca 2014 r., Ališić i inni v. Bośnia-Hercegowina, Chorwacja, Macedonia, Serbia i Słowenia.

48 Wyrok ETPC z dnia 28 czerwca 2018 r., G.I.E.M. S.R.L. i inni v. Włochy; Wyrok ETPC z dnia 24 
skarżący ponosi indywidualne i nadmierne obciążenie ${ }^{49}$.

Zasady prawa międzynarodowego o których mowa w art. 1 ust. 1 Protokołu $\mathrm{Nr} 1$ dotyczą wprawdzie cudzoziemców i nakazują dokonywanie wywłaszczeń tylko i wyłącznie za odszkodowaniem. Nie oznacza to jednak, że osoby niebędące cudzoziemcami mogą być arbitralnie pozbawiane przez państwo własności bez odszkodowania.

Zasady przyznawania odszkodowania obowiązujące w prawodawstwie danego państwa mają kluczowe znaczenie dla oceny, czy zakwestionowany środek respektuje wymaganą sprawiedliwą równowagę oraz czy nie nakłada nieproporcjonalnego obciążenia na skarżącego. Art. 1 Protokołu $\mathrm{Nr} 1$ nie gwarantuje jednak prawa do pełnego odszkodowania w wysokości odzwierciedlającej wartość rynkową wywłaszczonego mienia ${ }^{50}$.

\section{Ocena prawna wywłaszczeń dokonanych przed ratyfikacją Protokołu Nr 1}

Konwencja nie nałożyła na państwa obowiązku naprawy krzywd lub szkód wyrządzonych przed jej ratyfikacją ${ }^{51}$. Również art. 1 Protokołu $\mathrm{Nr} 1$ nie może być interpretowany w sposób nakładający co do zasady obowiązek przywracania własności, która została przeniesiona na państwo przed ratyfikacją Konwencji ${ }^{52}$.

Brak tego obowiązku wynika z okoliczności, że w myśl ogólnej zasady prawa międzynarodowego zawartej w art. 28 Konwencji wiedeńskiej o prawie traktatów z dnia 23 maja 1969 r. ${ }^{53}$ postanowienia traktatu nie są stosowane wstecz, chyba że strony wyraźnie postanowiły inaczej ${ }^{54}$. W przypadku EKPC należy podkreślić, że składa się ona nie tylko z wzajemnych ustaleń pomiędzy państwami, które ją ratyfikowały, lecz kreuje bezpośrednio prawa dla osób fizycznych objętych jurysdykcją tych państw. Zatem zasada niedziałania traktatów wstecz jest istotna nie tylko dla ETPC, ale także, przede wszystkim, dla sądów krajowych w chwili stosowania przez nie EKPC. ETPC, z uwagi na subsydiarną rolę w dziedzinie ochrony praw człowieka, powinien uważać, aby nie osiągnąć skutku równoznacznego $z$ doprowadzeniem organów władzy krajowej do stosowania EKPC $w_{s t e c z}{ }^{55}$. Dlatego ETPC wskazuje w orzecznictwie na okoliczność, że zgodnie z powszechnie uznanymi zasadami prawa międzynarodowego państwo może ponosić odpowiedzialność jedynie za zdarzenia, które nastąpiły po ratyfikowaniu EKPC ${ }^{56}$.

Art. 1 Protokołu Nr 1 nie nakłada żadnych ograniczeń na swobodę państwa w

października 1986 r., skarga nr 9118/80, AGOSI v. Wielka Brytania, LEX nr 81001.

49 Por. Wyrok ETPC z dnia 15 grudnia 2015 r., Matczyński v. Polska; Wyrok ETPC z dnia 13 grudnia 2016 r., Béláné Nagy v. Węgry.

50 Por. Wyrok ETPC z dnia 16 listopada 2004 r., Bruncrona v. Finlandia.

51 Wyrok ETPC z dnia 6 października 2015 r., skarga nr 26860/11, Krasnodębska-Kazikowska i Łuniewska v. Polska, LEX nr 1800237.

52 Decyzja ETPC z dnia 9 października 2012 r., Eparhija Budimljansko-nikšićka i inni v. Czarnogóra; Decyzja ETPC z dnia 5 kwietnia 2018 r., Kościół Chrześcijan Baptystów we Wrocławiu v. Polska; Decyzja ETPC z dnia 7 października 2008 r., Preussische Treuhand GmbH \& CO. Kg A. A. v. Polska; Decyzja ETPC z dnia 7 października 2008 r., Wyrok ETPC z dnia 28 września 2004 r., Kopecký v. Słowacja; Decyzja ETPC z dnia 2 marca 2005 r., Maltzan i inni, Zitzewitz i inni oraz Man Ferrostaal i Alfred Toepfer-Stiftung v. Niemcy.

53 Dz. U. z dnia 2 listopada 1990 r., Nr 74, poz. 439.

54 Art. 28 zatytułowany „Traktaty nie mają mocy wstecznej” brzmi następująco: „Jeżeli odmienny zamiar nie wynika z traktatu ani nie jest ustalony w inny sposób, jego postanowienia nie wiążą strony w odniesieniu do żadnej czynności lub zdarzenia, które miały miejsce, ani w odniesieniu do żadnej sytuacji, która przestała istnieć przed dniem wejścia w życie traktatu w stosunku do tej strony".

55 Wyrok ETPC z dnia 8 marca 2006 r., skarga nr 59532/00, Blečić v. Chorwacja, LEX nr 174501.

56 Por. Decyzja ETPC z dnia 27 stycznia 2000 r., Rucińska v. Polska. 
zakresie określania zakresu restytucji własności lub wyboru warunków, na jakich nastąpi zwrot praw majątkowych poprzednim właścicielom ${ }^{57}$. Państwa mają też szeroki margines uznania w odniesieniu do wyłączenia określonych kategorii dawnych właścicieli od uprawnienia do restytucji ${ }^{58}$. W różnych państwach po obaleniu ustroju komunistycznego przyjęto odmienne modele reprywatyzacji, wprowadzając ograniczenia $\mathrm{np}$. związane z określoną narodowością, miejscem zamieszkania ${ }^{59}$.

Jeżeli dane kategorie byłych właścicieli zostają wyłączone z kręgu podmiotów objętych reprywatyzacją, ich roszczenia restytucyjne nie mogą stanowić podstawy uprawnionej ekspektatywy, która korzysta z ochrony przewidzianej w art. 1 Protokołu $\mathrm{Nr}$ $1^{60}$. W tym zakresie warto wspomnieć, że ETPC potwierdził powyższą zasadę, wydając decyzję w sprawie Zamoyski-Brisson i inni v. Polska. ETPC odniósł się przy tym do wyroku wydanego w sprawie Broniowski v. Polska, wskazując, że fakt nadania przez ustawę krajową określonego uprawnienia zabużanom, jako jednej z kategorii skarżących, nie wymaga od państwa zapewnienia odszkodowania innej kategorii potencjalnych skarżących dochodzących zwrotu własności61.

Z drugiej strony należy pamiętać, że wolny wybór państw co do warunków, na jakich będą przywracać własność lub przyznawać odszkodowanie za skonfiskowaną przed ratyfikacją EKPC własność, nie oznacza, że ETPC nie ma kompetencji do zbadania, czy przyjęcie stosownej regulacji prawnej było zgodne z gwarancjami EKPC i jej Protokołów ${ }^{62}$. Przede wszystkim takie ustawodawstwo można uznać za źródło nowego prawa majątkowego chronionego przez art. 1 Protokołu $\mathrm{Nr}$ 1, które przysługuje osobom spełniającym wymogi przyznania takiego uprawnienia ${ }^{63}$.

Gdy państwo przyjmie takie rozwiązanie, musi być ono wdrażane z rozsądną przejrzystością i spójnością, aby uniknąć, tak dalece, jak to jest możliwe, pojawienia się niepewności i niejasności wśród osób, których dotyczą środki wdrożone przez państwo ${ }^{64}$.

\section{Podsumowanie}

Polska nie ma na podstawie art. 1 Protokołu $\mathrm{Nr} 1$ obowiązku przyjmowania ustaw przewidujących przywrócenie poprzedniego stanu prawnego, restytucję skonfiskowanej

57 Decyzja ETPC z dnia 5 kwietnia 2018 r., Kościół Chrześcijan Baptystów we Wrocławiu v. Polska; Wyrok ETPC z dnia 4 marca 2003 r., Jantner v. Słowacja; Decyzja ETPC z dnia 7 października 2008 r., Preussische Treuhand $\mathrm{GmbH} \& \mathrm{CO}$. Kg A. A. v. Polska; Wyrok ETPC z dnia 28 września 2004 r., Kopecký v. Słowacja; Decyzja ETPC z dnia 9 października 2012 r., Eparhija Budimljansko-nikšićka i inni v. Czarnogóra.

58 Wyrok ETPC z dnia 9 lutego 2012 r., skarga nr 42856/06, Kinský v. Czechy, LEX nr 1107808; Decyzja ETPC z dnia 5 kwietnia 2018 r., Kościół Chrześcijan Baptystów we Wrocławiu v. Polska.

59 R. Grzeszczak, Problematyka roszczeń majątkowych $w$ stosunkach polsko-niemieckich (http://robertgrzeszczak.bio.wpia.uw.edu.pl/files/2012/10/PROBLEMATYKA-ROSZCZE\%C5\%83-MAJ $\%$ C4\%84TKOWYCH.pdf) [data dostępu: 21 lipca 2019 r.].

60 Decyzja ETPC z dnia 5 kwietnia 2018 r., Kościół Chrześcijan Baptystów we Wrocławiu v. Polska; Wyrok ETPC z dnia 28 września 2004 r., Kopecký v. Słowacja; Wyrok ETPC z dnia 22 sierpnia 2006 r., skarga nr 7352/03, Beshiri i inni v. Albania, LEX nr 192726.

61 Decyzja ETPC z dnia 12 września 2017 r., skarga nr 19875/13, Zamoyski-Brisson i inni v. Polska, LEX nr 2365196.

62 Por. Wyrok ETPC z dnia 7 stycznia 2003 r., Kopecký v. Słowacja.

63 Decyzja ETPC z dnia 9 października 2012 r., Eparhija Budimljansko-nikšićka i inni v. Czarnogóra; Wyrok ETPC z dnia 22 sierpnia 2006 r., Beshiri i inni v. Albania; Wyrok ETPC z dnia 28 września 2004 r., Kopecký v. Słowacja.

64 Por. Wyrok ETPC z dnia 7 lipca 2009 r., Plechanow v. Polska; Wyrok ETPC z dnia 24 marca 2009 r., skarga nr 21911/03, Tudor v. Rumunia, LEX nr 486973. 
własności ani przyznanie odszkodowania za utraconą własność. ETPC uznał swobodę ustawodawcy co do tzw. rozliczenia z przeszłością w sprawach majątkowych, jeżeli nacjonalizacja została przeprowadzona przed ratyfikacją Protokołu $\mathrm{Nr} 1$ przez państwo. Tym bardziej orzecznictwo EKPC nie wskazuje na konieczność dokonania kompleksowej reprywatyzacji, która odniosłaby się do wszelkich kategorii mienia dotkniętego nacjonalizacją.

Analiza decyzji i wyroków ETPC w sprawach dotyczących naruszenia art. Protokołu $\mathrm{Nr} 1$ pozwala na dostrzeżenie okoliczności, że inna jest sytuacja osób dotkniętych nacjonalizacją, w przypadku których akty wywłaszczeniowe zostały uznawane za nieważne ex tunc, inna w przypadku osób które mają jedynie nadzieję na zmianę krajowego ustawodawstwa. W innej sytuacji znajdują się te osoby, które powołują się na odosobnione przypadki uznania przez sąd zasadności roszczeń wydanych w podobnych sprawach, podczas gdy nie można wykazać jednolitej linii orzeczniczej, która uznawałaby prawnie uzasadnioną ekspektatywę do zwrotu mienia lub odszkodowania. W zupełnie innej sytuacji znajdują się z kolei osoby w przypadku których istnieją roszczenia oparte na przepisach obowiązujących po ratyfikacji Protokołu Nr. 1, a jedynie nie udaje im się skutecznie uzyskać przysługującego prawa z uwagi na uchybienia proceduralne sądów, przewlekłość postępowań itp.

\section{Streszczenie:}

W artykule została pominięta ocena przyczyn braku przyjęcia przez ustawodawcę przez trzy dekady kompleksowej ustawy reprywatyzacyjnej. Artykuł skupia się jedynie na analizie zagadnienia ewentualnej konieczności przyjęcia ustawy reprywatyzacyjnej w Polsce w świetle regulacji art. 1 Protokołu Nr 1 do EKPC. Przeanalizowano wyroki i decyzje Europejskiego Trybunału Praw Człowieka, które dotyczą wykładni $\mathrm{i}$ stosowania art. 1. Uwzględnione zostały w tym zakresie postępowania, w których skarżący kwestionowali legalność oraz skutki nacjonalizacji przeprowadzonych podczas komunistycznego reżimu.

Polska ratyfikowała dnia 10 października 1994 r. Protokół Nr 1 do EKPC. Z uwagi na okoliczność dokonania nacjonalizacji przed ratyfikacją Protokołu $\mathrm{Nr} 1$, Polska nie ma na podstawie art. 1 Protokołu Nr 1 obowiązku przyjmowania ustawy reprywatyzacyjnej.

Słowa kluczowe:

sprawiedliwość okresu przejściowego, komunizm, reprywatyzacja, EKPC, art. 1 Protokołu Nr 1.

\section{Abstract:}

The issue of obligation to enact the reprivatisation law according to the Article 1 of Protocol No. 1 to the ECHR

The paper excludes the disputes related to the lack of enacting the reprivatisation law in Poland during the last 30 years. The paper focuses only on the obligation to enact the reprivatisation law according to the Article 1 of Protocol No. 1 to the ECHR. The paper exams the judgements and decisions of the European Court of Human Rights which concern the right to property guaranteed by Article 1 of Protocol No. 1. The point of the paper's deliberations is especially an analysis of the cases which complaints are related to restoration of property confiscated under the communist regime.

Poland ratified Protocol No. 1 to the ECHR on 10 October 1994. Because the nationalisation of private properties took place in the period before the ratification by Poland, there is no obligation to enact the reprivatisation law according to the Article 1 of Protocol No. 1.

Key words:

transitional justice, communism, reprivatisation, ECHR, Article 1 of Protocol No. 1, Poland

\section{Bibliografia:}

\section{Akty prawa międzynarodowego}

Europejska Konwencja o Ochronie Praw Człowieka i Podstawowych Wolności z dnia 4 listopada 1950 r. (Dz. U. z dnia 10 lipca 1993 r., Nr 61, poz. 284).

Konwencja wiedeńska o prawie traktatów z dnia 23 maja 1969 r. (Dz. U. z dnia 2 listopada 1990 r., Nr 74, poz. 439).

Protokół Nr 1 z dnia 20 marca 1952 r. do Konwencji o Ochronie Praw Człowieka i Podstawowych Wolności (Dz. U. z dnia 4 kwietnia 1995 r., Nr 36, poz. 175). 
Kwestia konieczności przyjęcia ustawy reprywatyzacyjnej w świetle art. 1 Protokołu Nr 1 do EKPC

\section{Decyzje ETPC}

Decyzja ETPC z dnia 11 grudnia 2018 r., skarga nr 41178/12, Rał v. Polska, LEX nr 2627060.

Decyzja ETPC z dnia 5 kwietnia 2018 r., skarga nr 32045/10, Kościół Chrześcijan Baptystów we Wrocławiu v. Polska, LEX nr 2467650.

Decyzja ETPC z dnia 13 marca 2018 r., skarga nr 45651/11, Dobrowolski i inni v. Polska, LEX nr 2467651.

Decyzja ETPC z dnia 23 stycznia 2018 r., skarga nr 12792/13, Wysowska v. Polska, LEX nr 2442318.

Decyzja ETPC z dnia 3 października 2017 r., skarga nr 1680/08, Lubelska Fabryka Maszyn i Narzędzi Rolniczych 'Plon' i inni v. Polska, LEX nr 2381150.

Decyzja ETPC z dnia 12 września 2017 r., skarga nr 19875/13, Zamoyski-Brisson i inni v. Polska, LEX nr 2365196.

Decyzja ETPC z dnia 2 maja 2017 r., skarga nr 55537/10, Haupt v. Austria, LEX nr 2297380.

Decyzja ETPC z dnia 17 maja 2016 r., skarga nr 8585/13, Piekarska i inni v. Polska, LEX nr 2051117.

Decyzja ETPC z dnia 17 grudnia 2013 r., skarga nr 49893/07, Crash 2000 OOD i inni v. Bułgaria, LEX nr 1409586.

Decyzja ETPC z dnia 23 października 2012 r., skarga nr 34880/12, N. K. M. v. Węgry, LEX nr 1285616.

Decyzja ETPC z dnia 9 października 2012 r., skarga nr 26501/05, Eparhija Budimljansko-nikšićka i inni v. Czarnogóra, LEX nr 1285512.

Decyzja ETPC z dnia 6 grudnia 2011 r., skarga nr 44232/11, Mihăieş i Senteş v. Rumunia, LEX nr 1101154.

Decyzja ETPC z dnia 7 października 2008 r., skarga nr 47550/06, Preussische Treuhand GmbH \& CO. Kg A.

A. v. Polska, LEX nr 457001.

Decyzja ETPC z dnia 2 marca 2005 r., skargi nr 71916/01, 71917/01, 10260/02, Maltzan i inni, Zitzewitz i inni oraz Man Ferrostaal i Alfred Toepfer-Stiftung v. Niemcy, LEX nr 147231.

Decyzja ETPC z dnia 19 grudnia 2002 r., skarga nr 31443/96, Broniowski v. Polska, LEX nr 56798.

Decyzja ETPC z dnia 13 grudnia 2000 r., skarga nr 33071/96, Malhous v. Czechy, LEX nr 148771.

Decyzja ETPC z dnia 6 kwietnia 2000 r., skarga nr 33776/96, P. Potocka, P. Potocki, D. Potocka-Radziwiłł, A. Potocka i I. d'Ornano v. Polska, LEX nr 41143.

Decyzja ETPC z dnia 27 stycznia 2000 r., skarga nr 33752/96, Rucińska v. Polska, LEX nr 41130.

\section{Wyroki ETPC}

Wyrok ETPC z dnia 28 czerwca 2018 r., skarga nr 1828/06, G.I.E.M. S.R.L. i inni v. Włochy, LEX nr 2508455.

Wyrok ETPC z dnia 13 grudnia 2016 r., skarga nr 53080/13, Béláné Nagy v. Węgry, LEX nr 2165716.

Wyrok ETPC z dnia 15 grudnia 2015 r., skarga nr 32794/07, Matczyński v. Polska, LEX nr 1936311.

Wyrok ETPC z dnia 6 października 2015 r., skarga nr 26860/11, Krasnodębska-Kazikowska i Łuniewska v. Polska, LEX nr 1800237.

Wyrok ETPC z dnia 16 lipca 2014 r., skarga nr 60642/08, Ališić i inni v. Bośnia-Hercegowina, Chorwacja, Macedonia, Serbia i Słowenia, LEX nr 1487006.

Wyrok ETPC z dnia 14 maja 2013 r., skarga nr 66529/11, N. K. M. v. Węgry, LEX nr 1771580.

Wyrok ETPC z dnia 7 lutego 2013 r., skarga nr 16574/08, Fabris v. Francja, LEX nr 1260966.

Wyrok ETPC z dnia 7 czerwca 2012 r., skarga nr 38433/09, Centro Europa 7 S.r.l. i Di Stefano v. Włochy, LEX nr 1164402.

Wyrok ETPC z dnia 29 maja 2012 r., skarga nr 2489/09, Flores Cardoso v. Portugalia, LEX nr 1164651.

Wyrok ETPC z dnia 17 kwietnia 2012 r., skarga nr 31925/08, Grudić v. Serbia, LEX nr 1147983.

Wyrok ETPC z dnia 9 lutego 2012 r., skarga nr 42856/06, Kinský v. Czechy, LEX nr 1107808.

Wyrok ETPC z dnia 21 czerwca 2011 r., skarga nr 46575/09, Bellizzi v. Malta, LEX nr 846299.

Wyrok ETPC z dnia 20 maja 2010 r., skarga nr 55555/08, Lelas v. Chorwacja, LEX nr 578480.

Wyrok ETPC z dnia 7 lipca 2009 r., skarga nr 22279/04, Plechanow v. Polska, LEX nr 504446.

Wyrok ETPC z dnia 24 marca 2009 r., skarga nr 21911/03, Tudor v. Rumunia, LEX nr 486973.

Wyrok ETPC z dnia 22 sierpnia 2006 r., skarga nr 7352/03, Beshiri i inni v. Albania, LEX nr 192726.

Wyrok ETPC z dnia 8 marca 2006 r., skarga nr 59532/00, Blečić v. Chorwacja, LEX nr 174501.

Wyrok ETPC z dnia 6 października 2005 r., skarga nr 1513/03, Draon v. Francja, LEX nr 157767.

Wyrok ETPC z dnia 16 listopada 2004 r., skarga nr 41673/98, Bruncrona v. Finlandia, LEX nr 142265.

Wyrok ETPC z dnia 28 września 2004 r., skarga nr 44912/98, Kopecký v. Słowacja, LEX nr 141516.

Wyrok ETPC z dnia 22 czerwca 2004 r., skarga nr 31443/96, Broniowski v. Polska, LEX nr 122528.

Wyrok ETPC z dnia 4 marca 2003 r., skarga nr 39050/97, Jantner v. Słowacja, LEX nr 77471.

Wyrok ETPC z dnia 7 stycznia 2003 r., skarga nr 44912/98, Kopecký v. Słowacja, LEX nr 75679.

Wyrok ETPC z dnia 23 marca 1995 r., skarga nr 15318/89, Loizidou v. Turcja, LEX nr 80428.

Wyrok ETPC z dnia 24 października 1986 r., skarga nr 9118/80, AGOSI v. Wielka Brytania, LEX nr 81001. 


\section{Literatura}

Balcerzak M., Odpowiedzialność państwa-strony Europejskiej konwencji o ochronie praw człowieka $i$ podstawowych wolności. Studium prawnomiędzynarodowe, Wydawnictwo Dom Organizatora, Toruń 2013.

Ciesielska M., Zakaz dyskryminacji i zasada równości w regionalnych systemach ochrony praw człowieka na przykładzie Europejskiej Konwencji Praw Człowieka i Arabskiej Karty Praw Człowieka [w:] Ochrona praw człowieka w wymiarze regionalnym, red. M. Marcinko, Ośrodek Międzynarodowego Prawa Humanitarnego i Praw Człowieka Wydziału Prawa i Administracji Uniwersytetu Jagiellońskiego, Kraków 2012, s. 22-34.

Czaplińska A., Określanie własnej kompetencji przez sądy międzynarodowe - granica czy przejaw swobody orzeczniczej? [w:] Granice swobody orzekania sądów międzynarodowych, red. A. Wyrozumska, Seria Wydawnicza Katedry Europejskiego Prawa Konstytucyjnego Wydział Prawa i Administracji Uniwersytetu Łódzkiego, Łódź 2014, s. 83-106.

Dobrzeniecki K., Romanowski M., Reprywatyzacja: problemy tworzenia i stosowania prawa, Wydawnictwo Uniwersytetu Kardynała Stefana Wyszyńskiego, Warszawa 2015.

Duda Ł., Kociubiński J., Realizacja ochrony własności w Europejskiej Konwencji Praw Człowieka na podstawie orzeczenia Lithgow i inni (http://www.bibliotekacyfrowa.pl/Content /34400/0015.pdf) [data dostępu: 25 lipca 2019 r.].

Góralski W. M., Przejęcie własności niemieckiej przez Państwo Polskie po drugiej wojnie światowej na Ziemiach Zachodnich i Północnych a niemieckie roszczenia odszkodowawcze, Warszawa 2004 (http://uwlaszczenia.gabo.pl/dok1.php?id=126) [data dostępu: 20 lipca 2019 r.].

Grzeszczak R., Problematyka roszczeń majątkowych w stosunkach polsko-niemieckich (http://robertgrzeszczak.bio.wpia.uw.edu.pl/files/2012/10/PROBLEMATYKA-ROSZCZE\%C 5\%83-MAJ \%C4\%84TKOWYCH.pdf) [data dostępu: 21 lipca 2019 r.].

Nowicki M. A., Komentarz do art. 1 Protokołu Nr 1 do Konwencji o ochronie praw człowieka i podstawowych wolności, LEX 2017.

Przybyszewski K., Prawa człowieka w kontekstach kulturowych, Wydawnictwo Naukowe Instytutu Filozofii Uniwersytetu im. Adama Mickiewicza w Poznaniu, Poznań 2010.

Rudzka J., Semenowicz A., Stawicki R., Problematyka reprywatyzacji w świetle projektów ustaw w latach 1989-2010, ze szczególnym uwzględnieniem propozycji ostatnich regulacji, Biuro Analiz i Dokumentacji Kancelarii Senatu, Warszawa 2010.

Sobański P., Roszczenia Polski wobec RFN w świetle doktryny niemieckiej, Wydawnictwo Naukowe Wyższej Szkoły Pedagogiki i Administracji im. Mieszka I w Poznaniu, Poznań 2019.

Zagórowska V., Odpowiedzialność państwa za naruszenie praw mniejszości narodowych - słabości międzynarodowego systemu ich ochrony [w:] Odpowiedzialność międzynarodowa w związku z naruszeniami praw człowieka i międzynarodowego prawa humanitarnego, red. M. Balcerzak, J. Kapelańska-Pręgowska, Katedra Praw Człowieka, Wydział Prawa i Administracji, Uniwersytet Mikołaja Kopernika, Toruń 2016, s. 207220. 